\title{
Psychometric evaluation of medication safety competence scale for clinical nurses
}

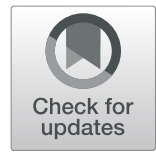

Zhen Yang ${ }^{1}$, Fengmin Chen ${ }^{2}$ Yingying Lu' ${ }^{1}$ and Huijun Zhang ${ }^{1 *}$

\begin{abstract}
Background: Nurses are the most important members of the health care system for medication safety, there are few tools to evaluate their medication safety competence. This study aimed to translate the Medication Safety Competence Scale into Chinese and validate its reliability and validity among clinical nurses.

Methods: A total of 894 clinical nurses were recruited from three cities in China. The original version of the Medication Safety Competence Scale was translated into Chinese using the backward and forward translation procedure. The reliability of the scale was measured by internal consistency, split-half reliability, and stability. The validity of the scale was assessed by the content validity index, exploratory factor analysis and confirmatory factor analysis.

Results: The Cronbach's coefficient of the scale was 0.940, and the coefficient values for the six domains ranged between 0.843 and 0.948 . The split-half reliability and stability were 0.671 and 0.703 , respectively. The content validity index of the scale was 0.952 . The 6-factor structure, supported by the eigenvalues, total variance explained, and scree plot accounted for $71.485 \%$ of the total variance. Moreover, as a result of the confirmatory factor analysis, the average variance extracted values were 0.55 to 0.70 , and the model fitting indexes were all in the acceptable range.

Conclusions: The Chinese version of the Medication Safety Competence Scale had ideal reliability and validity among clinical nurses. The evaluation results of the scale can provide a reference for nursing managers to formulate education plans and intervention measures to improve clinical nurses' safe medication competence.
\end{abstract}

Keywords: Medication safety competence, Factor analysis, Medication errors, Psychometric properties, Nurses

\section{Background}

Medication is the largest area in the course of treatment, and it is also the area with the most medical errors. The World Health Organization (WHO) reported that medication errors, as a preventable event, account for $20 \%$ of medical errors and launched global effort to halve medication-related errors in 5 years [1]. Adverse medication safety events may occur in the links of medical advice, nursing medication and patient health education $[2$, 3]. The investigation showed that drug use errors in

\footnotetext{
*Correspondence: 13904069606@163.com

'Department of Nursing, Jinzhou Medical University, No.40, Section 3, Songlu Road, Linghe District, Jinzhou 121001, China

Full list of author information is available at the end of the article
}

medication errors accounted for $50.0 \%$, followed by drug configuration errors accounted for $18.0 \%$ [4]. Moreover, according to the practice for medication safety issued by the Federal University of Sao Paulo, medication errors or adverse events account for $7.0 \%$ of hospitalizations in the health system, and at least 44,000 to 98,000 deaths per year are caused by medication errors in the United States, which cost 17 billion to 29 billion dollars [5]. Medication safety has become a key topic of global concern.

Medication safety is defined as the protection from accidental injury and the avoidance of any preventable and adverse events during drug use, realising the maximum therapeutic effect and producing the minimum adverse

(c) The Author(s). 2021 Open Access This article is licensed under a Creative Commons Attribution 4.0 International License, which permits use, sharing, adaptation, distribution and reproduction in any medium or format, as long as you give appropriate credit to the original author(s) and the source, provide a link to the Creative Commons licence, and indicate if changes were made. The images or other third party material in this article are included in the article's Creative Commons licence, unless indicated otherwise in a credit line to the material. If material is not included in the article's Creative Commons licence and your intended use is not permitted by statutory regulation or exceeds the permitted use, you will need to obtain permission directly from the copyright holder. To view a copy of this licence, visit http://creativecommons.org/licenses/by/4.0/ The Creative Commons Public Domain Dedication waiver (http://creativecommons.org/publicdomain/zero/1.0/) applies to the data made available in this article, unless otherwise stated in a credit line to the data. 
reactions [6]. Meanwhile, it puts forward the operational concept for establishing medication safety through effective assessment, accurate medication selection and use in the right method, dose and time, paying attention to drug contraindications, adverse reactions, interactions, etc., to achieve the purpose of safety, rationality, effectiveness and economy $[7,8]$. The purpose of safe medication is to take patients as the center, provide comprehensive medication service for patients, ensure the rationality of medication and improve the health level of patients [9]. Nurses are recognized as the most important group for clinical medication safety globally $[10,11]$. In addition, medication safety is an important part of patient safety $[12,13]$. Therefore, we should focus on nurses' positive role in patient safety and medication safety competence under the high prevalence of medication errors.

Medication safety education programs have been developed and implemented among nursing students [14-17]. However, there are few studies on nurses' medication safety competence in clinical nursing practice, and relevant measurement tools have not been developed in China. Based on the eight stages of scale development and verification [18], Korean scholar Seomun recently combined patient safety with clinical medication nursing in the development of the Medication Safety Competence Scale (MSCS) for nurses in July 2020 [19]. The development of the MSCS has arisen out of this need to assess nurses' competence on the relevant knowledge, skills, and attitudes for medication safety that can contribute to clinical practice, research, and education. In addition, the scale supported by a six-factor structure provides a comprehensive and effective assessment of medication safety competence from multiple levels and perspectives, which makes up for the deficiency of a single dimensional measurement tool. This study aimed to translate the MSCS into Chinese and validate its reliability and validity among clinical nurses in the context of the high prevalence of medication errors.

\section{Methods}

\section{Study design and participants}

The design of this study was a methodological approach to translate the Medication Safety Competence Scale and to evaluate its psychometric properties with a multicentric cross-sectional survey from March 2021 to May 2021. The sample size was determined using the general rule for factor analytic procedure that requires a minimum of 10 respondents per item [20], but a larger sample is desirable. In this study, 20 respondents per item were required to ensure the accuracy of exploratory factor analysis and confirmatory factor analysis. Participants were recruited by convenience sampling with the assistance of nursing directors from different hospitals. A total of 894 nurses involved in clinical nursing practice were included in the study.

\section{Instruments \\ General Demographic Characteristics Questionnaire}

A thorough literature review was conducted, after which the team designed the General Demographic Characteristics Questionnaire. Participants were required to complete the questionnaire consisting of six items by self-reporting: age, gender, educational level, marital status, site, and professional experience.

\section{Medication Safety Competence Scale}

Medication safety competence was measured through the Medication Safety Competence Scale developed by Seomun [19]. The scale includes thirty-six items measured on a Likert scale from 1 to 5 , corresponding to (1) definitely no, (2) rather no, (3) hard to say, (4) rather yes, and (5) definitely yes. Six domains were evaluated: medication management and patient assessment, improvement of safety problems in the medication process, management of effecting factors, management of safety risks, multidisciplinary collaboration, and responsibility as a professional nurse. The Cronbach's $\alpha$ coefficient of the scale was 0.96 , with those of domains ranging from 0.77 to 0.91 .

\section{Procedures}

\section{Scale translation procedure}

Our translation work has obtained professor Seomun's permission. First, the Medication Safety Competence Scale was translated into Chinese by two Chinese professors majoring in English language. Then, two Chinese teachers who are native English speakers did the reverse translation. Psychological experts made further adjustments for the translated scale. A preliminary survey using the translated scale was conducted with 12 nurses to verify the clarity and understanding of the scale.

\section{Data collection procedure}

After receiving appropriate training, researchers went to three cities respectively and recruited participates with the assistance of nursing directors. According to the pre-investigation, we were able to contact about 1200 nurses from the three same-level hospitals in the three cities of Northeast China during the study period. 1042 eligible nurses were invited to participate in the crosssectional survey through convenience sampling, of which 955 agreed to participate. The participants were placed in a quiet classroom to fill out questionnaires anonymously. A total of 894 completed questionnaires were eventually obtained after the removal of invalid ones (Fig. 1). 


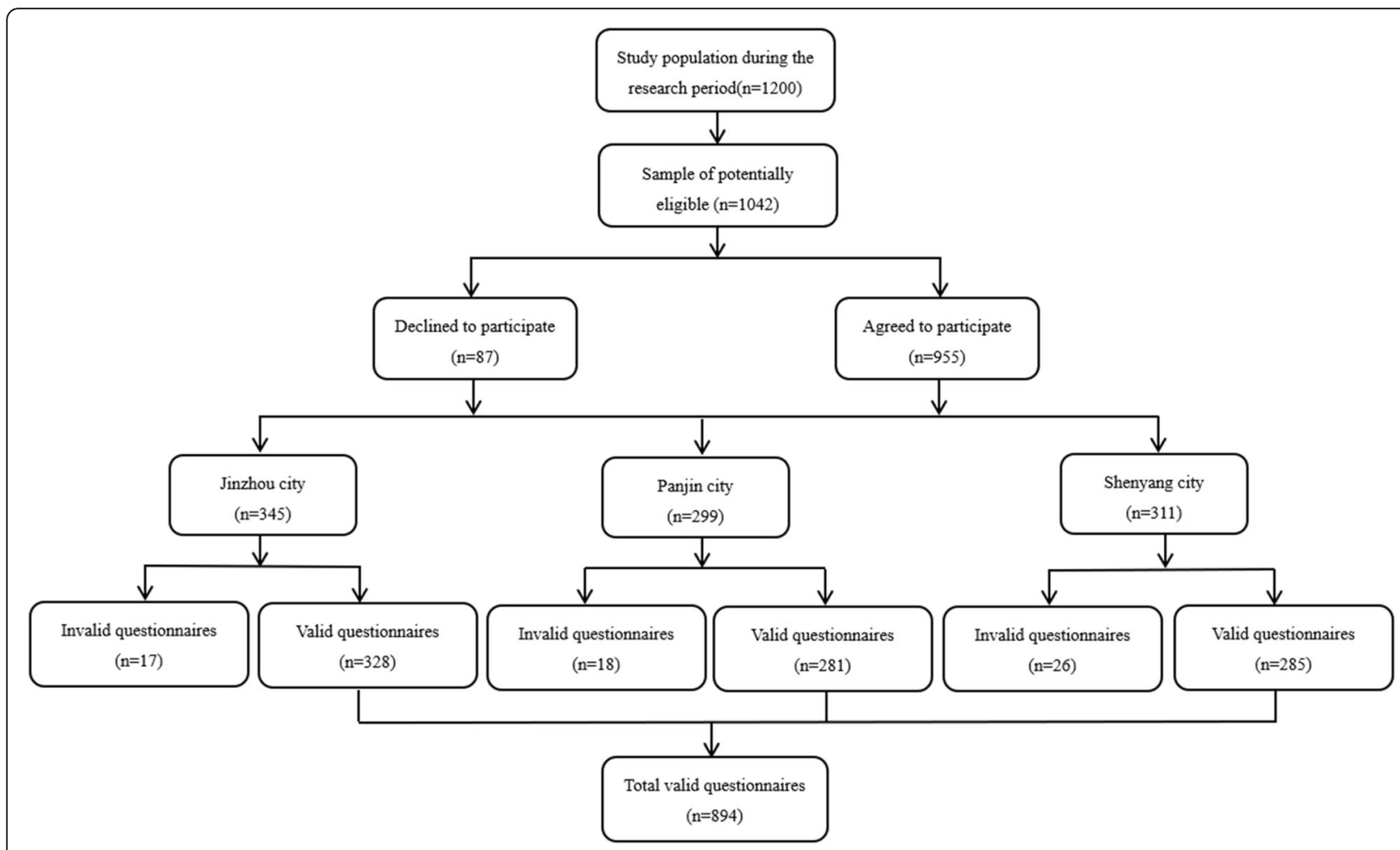

Fig. 1 Flowchart of participants

\section{Data analysis}

Statistical analysis was performed using the SPSS software (v. 22.0) and AMOS (v. 21.0). Continuous data were described as mean (standard deviation), categorical data were expressed as percentages. Mardia's Skewness \& Kurtosis tests were used to determine whether the data have a multivariate normal distribution. When the results of skewness and kurtosis tests are significant $(P>$ $0.05)$ and the standardized multivar -iate kurtosis coefficient is less than 5 , the data can be considered to have a multivari -ate normal distribution [21].

\section{Items analysis}

For items analysis, the total score of the translated scale was ranked from high to poor, and the relationship between the first $27 \%$ (high-score group) and the last $27 \%$ (poor-score group) was analyzed to judge whether the translated scale has an ideal discrimination ability. The correlation between items and the translated scale and the Cronbach's $\alpha$ coefficient if item deleted were analysed to evaluate whether each item of the translated scale can be retained.

\section{Validity analysis}

Seven experts were invited to evaluate the content validity of the translated scale using the Delphi method. The content validity index of the items (I-CVI) and the content validity index of the scale (S-CVI) were calculated using the Lawshe's evaluation method. According to the correlation between each item and the theme, each item was given four ratings of "no correlation" (0 point), "somewhat correlated" (0 point), "quite correlated" (1 point), and "high correlation" (1 point). I-CVI is the ratio of the number of experts who ranked each item with 1 point to the total number of experts. S-CVI is the mean of I-CVI for all items.

To explore and validate the underlying factor structure of the translated scale, an exploratory factor analysis (EFA) and a confirmatory factor analysis (CFA) were performed. The sample of 894 cases was randomly subdivided into two groups, one $(n=447)$ for EFA and the other $(n=447)$ for CFA. Kaiser-Meyer-Olkin (KMO) measurement and Bartlett test of sphericity were used to judge the rationality of using principal component analysis (PCA) with varimax rotation in EFA. Varimax rotation is the most commonly used orthogonal technique that minimizes factor complexity with a maximized variance of factor loading. Only when the Bartlett test of sphericity was significant $(P<0.05)$ and the KMO was > 0.60 , the dataset was considered appropriate for PCA. The factors were extracted based on the comprehensive consideration of eigenvalues, explained total variance, and the visual inspection of the scree plot. Analysis of Moment Structure (AMOS) was used to confirm the 
hypothesized factor model in CFA. Convergent validity and discriminant validity were also analyzed for assessing construct validity among item measures.

\section{Reliability analysis}

The Cronbach's $\alpha$ coefficients of the translated scale and its dimensions were calculated to assess the internal consistency reliability. The items were divided according to the order of oddness and evenness, the split-half reliability was evaluated by testing the correlation between divided items. Two weeks later, the translated scale was used to assess its stability among 70 nurses. Test-retest correlation analysis was performed to assess the stability and consistency of the scale across the entire period of time during which data were collected. The Intraclass Correlation Coefficient (ICC) was calculated to assess intra- and interrater reliability of the scale.

\section{Ethical consideration}

All participants were informed of the objectives and the scope of the study and provided their informed consent for participation. All procedures were performed according to the Helsinki declaration of 1964 and its further modifications. The study protocol was approved by the Ethics Committee of the Jinzhou Medical University (LLSC2021213).

\section{Results}

\section{Descriptive statistics}

This study included 894 nurses: 233 males $(24.9 \%)$ and 671 females $(75.1 \%)$. Participants aged 25 to 34 years accounted for $51.8 \%$. More than half (61.1\%) of the participants were married; $45.7 \%$ of the participants had an undergraduate education. The proportion of participants who came from Jinzhou city was the largest $(36.7 \%)$; for the years of professional experience, $35.0 \%$ of participants have been in clinical care for 6 to10 years. The data have a multivariate normal distribution according to the result of Mardia's Skewness \& Kurtosis tests $(P>$ 0.05 and standardized multivaria -te kurtosis coefficient is 3.946). Other sociodemographic informations are shown in Table 1.

\section{Item analysis}

The critical ratio $>3.000$ indicated the higher discriminability of items. In this study, the critical ratio of 36 items were 9.818 to 26.010 , which indicating that the discrimination ability of each item was good. The scores of each item were positively correlated with the total score $(r=0.434$ to $0.722, P<0.001)$, indicated that each item was moderately correlated with the scale. After deleting each item, the Cronbach's $\alpha$ coefficients value of the translated scale were 0.936 to 0.939 , which does not
Table 1 Frequency distribution of demographic characteristics $(n=894)$

\begin{tabular}{|c|c|c|c|}
\hline Factors & Group & n & $\%$ \\
\hline \multirow[t]{4}{*}{ Age } & $18-24$ & 157 & 17.6 \\
\hline & $25-34$ & 463 & 51.8 \\
\hline & $35-44$ & 214 & 23.9 \\
\hline & $\geq 45$ & 60 & 6.7 \\
\hline \multirow[t]{2}{*}{ Sex } & Male & 223 & 24.9 \\
\hline & Female & 671 & 75.1 \\
\hline \multirow[t]{3}{*}{ Education level } & Junior college education & 257 & 28.8 \\
\hline & Undergraduate education & 409 & 45.7 \\
\hline & Postgraduate education & 228 & 25.5 \\
\hline \multirow[t]{3}{*}{ Marital status } & Unmarried & 273 & 30.5 \\
\hline & Married & 546 & 61.1 \\
\hline & Divorced/Widowed & 75 & 8.4 \\
\hline \multirow[t]{3}{*}{ Site } & Jinzhou city & 328 & 36.7 \\
\hline & Panjin city & 281 & 31.4 \\
\hline & Shenyang city & 285 & 31.9 \\
\hline \multirow[t]{5}{*}{ Professional experience (year) } & $1-5$ & 207 & 23.2 \\
\hline & $6-10$ & 313 & 35.0 \\
\hline & $11-15$ & 181 & 20.2 \\
\hline & $16-20$ & 114 & 12.8 \\
\hline & $\geq 20$ & 79 & 8.8 \\
\hline
\end{tabular}

exceed Cronbach's $\alpha$ value of the scale, indicating that the 36 items could be retained. (Table 2)

\section{Validity analysis \\ Content validity analysis}

Seven experts independently were invited to evaluate the content validity of the translated scale. The I-CVI and SCVI of the translated scale were calculated by using the Lawshe's evaluation method. The results showed that the I-CVIs obtained were 0.857 to 1.000 and the S-CVI was 0.952 .

\section{Exploratory factor analysis}

The Kaiser-Meyer-Olkin Measure of Sampling Adequacy was 0.853 , and the Bartlett test of sphericity was significant $\left(X^{2}=32217.515 ; P<0.001\right)$. Therefore, the matrix is not an identity matrix and is appropriate for factor extraction. As a result, 6 factors that explained a total of $71.485 \%$ of the variance had initial eigenvalues $>1$ each. The 6 -factor structure was further confirmed by the scree plot, as the descending tendency became weak after the sixth point (Fig. 2). After varimax rotation, the six factors explained $6.350 \%, 8.495 \%, 10.499 \%, 12.161 \%, 15.928 \%$, and $18.052 \%$ of the variance. The factor loadings are displayed in Table 3. 
Table 2 Item analysis for Chinese version of the Medication Safety Competence Scale

\begin{tabular}{|c|c|c|c|c|}
\hline Item & Item score (SD) & Critical ratio & Correlation coefficient between item and total score & Cronbach's Alpha if item deleted \\
\hline 1 & $2.45(0.92)$ & 21.968 & 0.631 & 0.937 \\
\hline 2 & $2.85(0.82)$ & 13.757 & 0.501 & 0.938 \\
\hline 3 & $2.90(0.85)$ & 26.010 & 0.696 & 0.937 \\
\hline 4 & $2.45(0.91)$ & 25.444 & 0.677 & 0.937 \\
\hline 5 & $2.90(0.80)$ & 19.573 & 0.587 & 0.938 \\
\hline 6 & $2.73(0.87)$ & 14.737 & 0.506 & 0.938 \\
\hline 7 & $2.77(0.85)$ & 20.833 & 0.640 & 0.937 \\
\hline 8 & $2.84(0.86)$ & 20.145 & 0.608 & 0.938 \\
\hline 9 & $2.54(0.92)$ & 24.320 & 0.668 & 0.937 \\
\hline 10 & $2.99(0.78)$ & 16.657 & 0.525 & 0.938 \\
\hline 11 & $3.07(0.77)$ & 17.242 & 0.515 & 0.938 \\
\hline 12 & $3.02(0.73)$ & 17.523 & 0.550 & 0.938 \\
\hline 13 & $3.01(0.76)$ & 19.855 & 0.568 & 0.938 \\
\hline 14 & $3.11(0.81)$ & 13.113 & 0.443 & 0.939 \\
\hline 15 & $3.22(0.77)$ & 13.587 & 0.455 & 0.939 \\
\hline 16 & $3.02(0.75)$ & 21.111 & 0.576 & 0.938 \\
\hline 17 & $2.97(0.77)$ & 15.407 & 0.476 & 0.939 \\
\hline 18 & $3.07(0.89)$ & 21.692 & 0.656 & 0.937 \\
\hline 19 & $3.41(0.85)$ & 16.659 & 0.556 & 0.938 \\
\hline 20 & $3.05(0.92)$ & 21.643 & 0.658 & 0.937 \\
\hline 21 & $2.72(0.89)$ & 18.939 & 0.581 & 0.938 \\
\hline 22 & $3.26(0.98)$ & 13.309 & 0.475 & 0.939 \\
\hline 23 & $3.03(0.97)$ & 12.677 & 0.455 & 0.939 \\
\hline 24 & $2.94(0.82)$ & 22.123 & 0.634 & 0.937 \\
\hline 25 & $2.95(0.78)$ & 21.565 & 0.633 & 0.937 \\
\hline 26 & $2.93(0.83)$ & 24.758 & 0.679 & 0.937 \\
\hline 27 & $2.97(0.78)$ & 22.670 & 0.661 & 0.937 \\
\hline 28 & $3.09(1.11)$ & 11.511 & 0.479 & 0.939 \\
\hline 29 & $2.98(0.87)$ & 19.314 & 0.582 & 0.938 \\
\hline 30 & $2.11(1.01)$ & 23.893 & 0.701 & 0.937 \\
\hline 31 & $2.00(0.93)$ & 14.884 & 0.573 & 0.938 \\
\hline 32 & $2.11(1.05)$ & 21.692 & 0.691 & 0.937 \\
\hline 33 & $2.09(1.05)$ & 24.522 & 0.722 & 0.936 \\
\hline 34 & $3.46(0.80)$ & 12.767 & 0.451 & 0.939 \\
\hline 35 & $3.33(0.86)$ & 9.818 & 0.434 & 0.939 \\
\hline 36 & $3.42(0.78)$ & 11.415 & 0.495 & 0.938 \\
\hline
\end{tabular}

\section{Confirmatory factor analysis}

The results of confirmatory factor analysis are shown in Fig. 3. According to the modification indices (MI), the initial model was modified in consecutive steps: e3 and e7, e7 and e14, e10 and e15, e12 and e17, e19 and e22, e19 and e23, e25 and e29, respectively. In the final model fitness index (original model fitness index), the chi-square degree of freedom $\left(\chi^{2} / \mathrm{df}\right)$ was 2.939 (5.568), the goodness-of-fit index (GFI) was 0.915 (0.774), the adjusted goodness-of-fit index (AGFI) was 0.901 (0.708), the root mean square error of approximation (RMSEA) was 0.047 (0.084), the tucker lewis index (TLI) was 0.962 (0.795), the comparative fit index (CFI) was 0.969 (0.821), the incremental fit index (IFI) was 0.969 (0.821), the parsimonious goodness-of-fit index (PGFI) was 0.704 (0.612), and the parsimonious normed-of-fit index (PNFI) was 0.775 (0.717). The results of correlation analysis between factors are shown in Table 4. The construct reliability (CR) ranged between 0.87 and 0.94 , and the average variance extracted (AVE) values were $0.51-$ 0.77 . The correlation between factors ranged from 0.141 to 0.378 . 
Table 3 Factor loadings of exploratory factor analysis for the Medication Safety Competence Scale

Item ("I feel confident about. .")
1. Planning care in the medication process
2. Communicating individually according to patients' condition and level in the medication
process
3. Evaluating my nursing practice in the medication process
4. Giving confidence to patients and caregivers in the medication process
5. Giving a sense of stability through clear and consistent communication with patient
6. Documentation of assessment, planning, administration of medication, and evaluation of
outcomes
7. Effective patient training to help patients speak of the symptoms of adverse effects
8. Practicing medication care with responsibility for the safety of patients
9. Detecting adverse reactions in medication
10. Improving the complex and vulnerable way of medication safety (e.g., incorrect
administration practices)
11. Establish prevention measures when medication errors or near-misses occur
12. Trying to create a supportive environment that encourages people to talk about
problems when medication errors

\begin{tabular}{|c|c|c|c|c|c|}
\hline $\begin{array}{l}\text { Factor } \\
1\end{array}$ & $\begin{array}{l}\text { Factor } \\
2\end{array}$ & $\begin{array}{l}\text { Factor } \\
\mathbf{3}\end{array}$ & $\begin{array}{l}\text { Factor } \\
4\end{array}$ & $\begin{array}{l}\text { Factor } \\
5\end{array}$ & $\begin{array}{l}\text { Factor } \\
6\end{array}$ \\
\hline 0.796 & - & - & - & - & - \\
\hline 0.814 & - & - & - & - & - \\
\hline 0.757 & - & - & - & - & - \\
\hline 0.828 & - & - & - & - & - \\
\hline 0.855 & - & - & - & - & - \\
\hline 0.812 & - & - & - & - & - \\
\hline 0.776 & - & - & - & - & - \\
\hline 0.795 & - & - & - & - & - \\
\hline 0.820 & - & - & - & - & - \\
\hline - & 0.855 & - & - & - & - \\
\hline - & 0.833 & - & - & - & - \\
\hline - & 0.852 & - & - & - & - \\
\hline - & 0.838 & - & - & - & - \\
\hline - & 0.714 & - & - & - & - \\
\hline - & 0.682 & - & - & - & - \\
\hline - & 0.888 & - & - & - & - \\
\hline - & 0.756 & - & - & - & - \\
\hline - & - & - & 0.812 & - & - \\
\hline - & - & - & 0.652 & - & - \\
\hline - & - & - & 0.816 & - & - \\
\hline - & - & - & 0.573 & - & - \\
\hline - & - & - & 0.792 & - & - \\
\hline - & - & - & 0.758 & - & - \\
\hline - & - & 0.813 & - & - & - \\
\hline - & - & 0.825 & - & - & - \\
\hline - & - & 0.803 & - & - & - \\
\hline - & - & 0.802 & - & - & - \\
\hline - & - & 0.503 & - & - & - \\
\hline- & - & 0.809 & - & - & - \\
\hline - & - & - & - & 0.793 & - \\
\hline- & - & - & - & 0.751 & - \\
\hline - & - & - & - & 0.807 & - \\
\hline - & - & - & - & 0.805 & - \\
\hline - & - & - & - & - & 0.790 \\
\hline - & - & - & - & - & 0.861 \\
\hline - & - & - & - & - & 0.850 \\
\hline
\end{tabular}




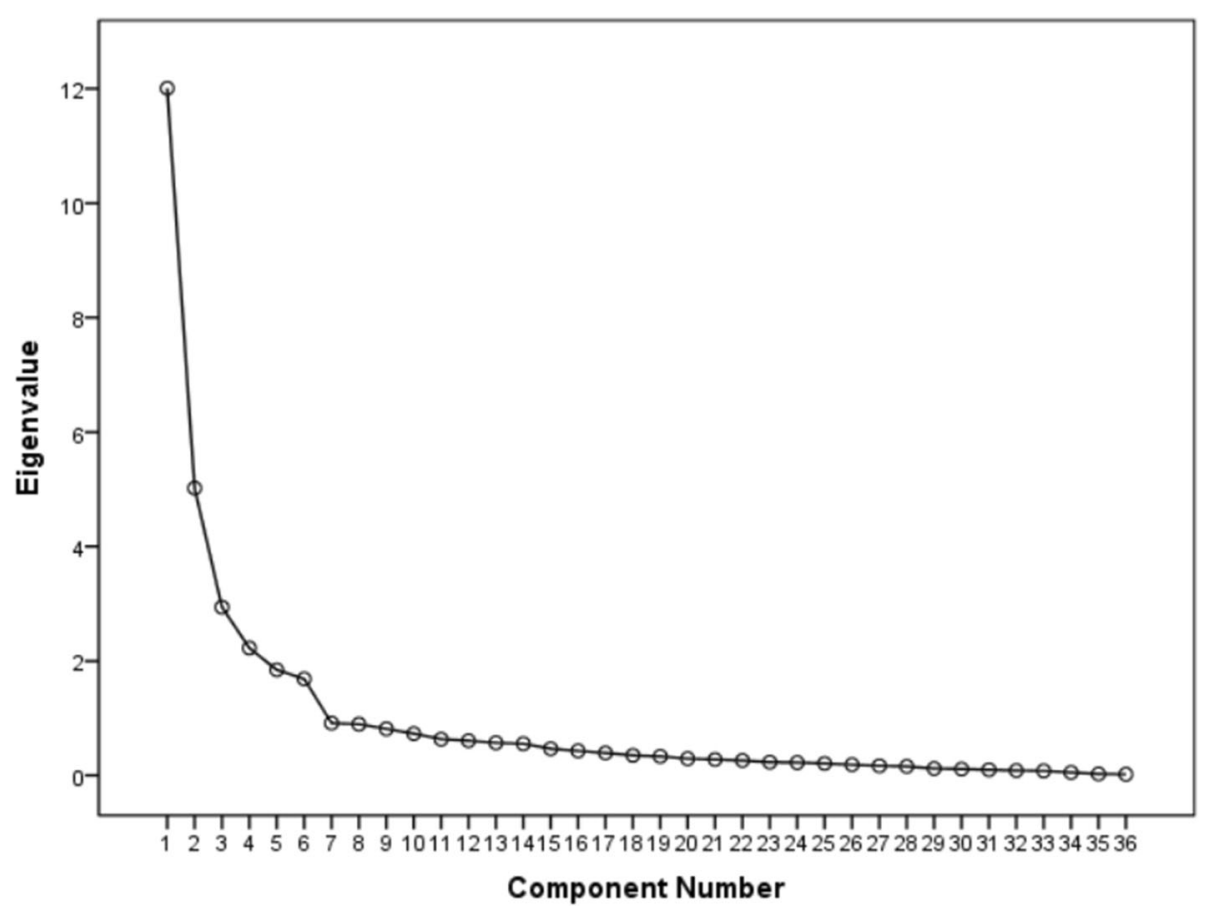

Fig. 2 Screen plot of exploratory factor analysis for Chinese version of the medication safety competence scale

\section{Reliability analysis}

The Cronbach's $\alpha$ coefficient of the translated scale was 0.940, the Cronbach's $\alpha$ coefficients of the dimensions ranged from 0.843 to 0.948 . The split-half reliability was 0.671. After two weeks, 70 nurses were randomly selected for retesting, the test-retest reliability was 0.703 and the ICC was 0.688 (Table 5).

\section{Discussion}

\section{The Chinese version of the scale has the suitable} distinction

The Chinese version of the Medication Safety Competence Scale was obtained in accordance with Chinese guidelines and common expressions. The preliminary survey and the main survey showed that the translated scale was clear and easy to understand. Furthermore, the critical ratio of the items is much better than the standard value [22]. The score of each item was positively correlated with the total score of the scale. The Cronbach's $\alpha$ coefficient did not exceed the original value of the translated scale after deleting each item, suggesting that all the 36 items should be retained.

\section{The Chinese version of the scale has suitable validity}

Validity refers to the extent to which the measured tool accurately corresponds to the real world [23]. We evaluated the validity of the scale by content and structure analyses. The Delphi method showed that I-
CVI and S-CVI were higher than the reference values [24]. It is generally believed that the ideal structure validity can be achieved by two different ways: (1) the factors extracted by exploratory analysis explain $40.00 \%$ or more of the total variation; (2) each item has a high load value of a single factor $(>0.400)$ and low values of the other factors. In this study, the six factors equivalent to the domains of the scale were extracted by exploratory factor analysis and explained $71.485 \%$ of the total data variation. Moreover, the CFA results confirmed the measurement validity of the translated scale [19]. The construct reliability ranged between 0.87 and 0.94 , which was higher than the reference value of 0.70 , demonstrating convergent validity [25]. Discriminant validity was also demonstrated because the squares of correlation coefficients between latent variables were smaller than the average variance extracted values [25]. Overall, the Chinese version of the scale showed optimal validity among clinical nurses.

\section{The Chinese version of the scale has the suitable reliability}

Reliability analysis reflects the fact that a scale should consistently reflect the construct it is measuring [26]. We evaluated the reliability of the Chinese version of the scale for three aspects: internal consistency reliability, split-half reliability, and stability. The results showed 
Table 4 Results of Confirmatory Factor Analysis

\begin{tabular}{|c|c|c|c|c|c|c|c|c|c|c|c|c|c|c|c|}
\hline \multirow[t]{2}{*}{ Factor } & \multirow[t]{2}{*}{ Item } & \multicolumn{5}{|c|}{ Parameter significance estimation } & \multicolumn{6}{|c|}{$\begin{array}{l}\text { Correlation between factors } \\
\text { (Discriminant Validity) }\end{array}$} & \multirow{2}{*}{$\begin{array}{l}\text { Factor } \\
\text { Reliability } \\
\text { SMC }\end{array}$} & \multirow{2}{*}{$\begin{array}{l}\text { Construct } \\
\text { Reliability } \\
\text { CR }\end{array}$} & \multirow{2}{*}{$\begin{array}{l}\text { Convergent } \\
\text { Validity } \\
\text { AVE }\end{array}$} \\
\hline & & $\begin{array}{l}\text { Unstd. } \\
\text { Estimate }\end{array}$ & S.E. & C.R. & $\mathbf{P}$ & $\begin{array}{l}\text { Std. } \\
\text { Estimate }\end{array}$ & $\overline{\mathrm{F} 1}$ & F2 & F3 & F4 & F5 & $\overline{F 6}$ & & & \\
\hline \multirow[t]{9}{*}{$\mathrm{F} 1$} & a1 & 1 & & & & 0.92 & 1 & & & & & & 0.85 & 0.94 & 0.63 \\
\hline & a2 & 0.63 & 0.03 & 23.45 & $<0.001$ & 0.63 & & & & & & & 0.40 & & \\
\hline & a3 & 0.76 & 0.03 & 24.79 & $<0.001$ & 0.76 & & & & & & & 0.58 & & \\
\hline & a4 & 1.06 & 0.02 & 63.98 & $<0.001$ & 0.93 & & & & & & & 0.86 & & \\
\hline & a5 & 0.72 & 0.03 & 27.53 & $<0.001$ & 0.72 & & & & & & & 0.52 & & \\
\hline & a6 & 0.74 & 0.03 & 29.34 & $<0.001$ & 0.73 & & & & & & & 0.53 & & \\
\hline & a7 & 0.74 & 0.03 & 25.82 & $<0.001$ & 0.73 & & & & & & & 0.53 & & \\
\hline & a8 & 0.81 & 0.03 & 29.87 & $<0.001$ & 0.74 & & & & & & & 0.55 & & \\
\hline & a9 & 1.07 & 0.02 & 45.93 & $<0.001$ & 0.92 & & & & & & & 0.85 & & \\
\hline \multirow[t]{8}{*}{ F2 } & a10 & 1 & & & & 0.75 & 0.180 & 1 & & & & & 0.56 & 0.92 & 0.60 \\
\hline & a11 & 1.14 & 0.04 & 26.89 & $<0.001$ & 0.81 & & & & & & & 0.66 & & \\
\hline & a12 & 0.98 & 0.03 & 36.29 & $<0.001$ & 0.76 & & & & & & & 0.58 & & \\
\hline & a13 & 1.18 & 0.04 & 27.72 & $<0.001$ & 0.94 & & & & & & & 0.88 & & \\
\hline & a14 & 0.9 & 0.04 & 23.77 & $<0.001$ & 0.66 & & & & & & & 0.44 & & \\
\hline & a15 & 0.74 & 0.03 & 21.43 & $<0.001$ & 0.61 & & & & & & & 0.37 & & \\
\hline & a16 & 1.28 & 0.04 & 29.99 & $<0.001$ & 0.94 & & & & & & & 0.88 & & \\
\hline & a17 & 0.87 & 0.04 & 19.69 & $<0.001$ & 0.63 & & & & & & & 0.40 & & \\
\hline \multirow[t]{6}{*}{ F3 } & a18 & 1 & & & & 0.95 & 0.346 & 0.376 & 1 & & & & 0.90 & 0.85 & 0.51 \\
\hline & a19 & 0.55 & 0.03 & 20.85 & $<0.001$ & 0.56 & & & & & & & 0.31 & & \\
\hline & a20 & 1.03 & 0.01 & 117.89 & $<0.001$ & 0.94 & & & & & & & 0.88 & & \\
\hline & a21 & 0.53 & 0.03 & 18.72 & $<0.001$ & 0.53 & & & & & & & 0.28 & & \\
\hline & a22 & 0.63 & 0.03 & 20.38 & $<0.001$ & 0.57 & & & & & & & 0.32 & & \\
\hline & a23 & 0.62 & 0.03 & 20.41 & $<0.001$ & 0.57 & & & & & & & 0.32 & & \\
\hline \multirow[t]{6}{*}{ F4 } & a24 & 1 & & & & 0.88 & 0.354 & 0.264 & 0.316 & 1 & & & 0.77 & 0.92 & 0.66 \\
\hline & a25 & 0.96 & 0.02 & 38.41 & $<0.001$ & 0.89 & & & & & & & 0.79 & & \\
\hline & a26 & 0.98 & 0.03 & 35.6 & $<0.001$ & 0.86 & & & & & & & 0.74 & & \\
\hline & a27 & 0.93 & 0.03 & 36.87 & $<0.001$ & 0.87 & & & & & & & 0.76 & & \\
\hline & a28 & 0.54 & 0.05 & 10.76 & $<0.001$ & 0.51 & & & & & & & 0.26 & & \\
\hline & a29 & 0.91 & 0.03 & 28.41 & $<0.001$ & 0.78 & & & & & & & 0.61 & & \\
\hline \multirow[t]{4}{*}{ F5 } & a30 & 1 & & & & 0.91 & 0.378 & 0.307 & 0.327 & 0.326 & 1 & & 0.83 & 0.93 & 0.77 \\
\hline & a31 & 0.72 & 0.03 & 26.53 & $<0.001$ & 0.71 & & & & & & & 0.50 & & \\
\hline & a32 & 1.05 & 0.02 & 44.62 & $<0.001$ & 0.91 & & & & & & & 0.83 & & \\
\hline & a33 & 1.1 & 0.02 & 49.98 & $<0.001$ & 0.95 & & & & & & & 0.90 & & \\
\hline \multirow[t]{3}{*}{ F6 } & a34 & 1 & & & & 0.80 & 0.141 & 0.254 & 0.325 & 0.372 & 0.227 & 1 & 0.64 & 0.85 & 0.65 \\
\hline & a35 & 1.06 & 0.05 & 22.81 & $<0.001$ & 0.78 & & & & & & & 0.61 & & \\
\hline & a36 & 1.03 & 0.04 & 23.76 & $<0.001$ & 0.84 & & & & & & & 0.71 & & \\
\hline
\end{tabular}

Note: AVE average variance extracted; $C R$ construct reliability; SMC Square of Multiple coefficient

that the Cronbach's $\alpha$ coefficient of the translated scale was higher than the original version [19], while the stability of the translated scale was found to be at a very favorable level. Overall, the Chinese version of the scale showed optimal reliability among clinical nurses.

\section{Limitations}

There are some limitations to this study, which should be noted and discussed. First, we did not investigate factors influencing the medication safety competence among clinical nurses, which will be of 


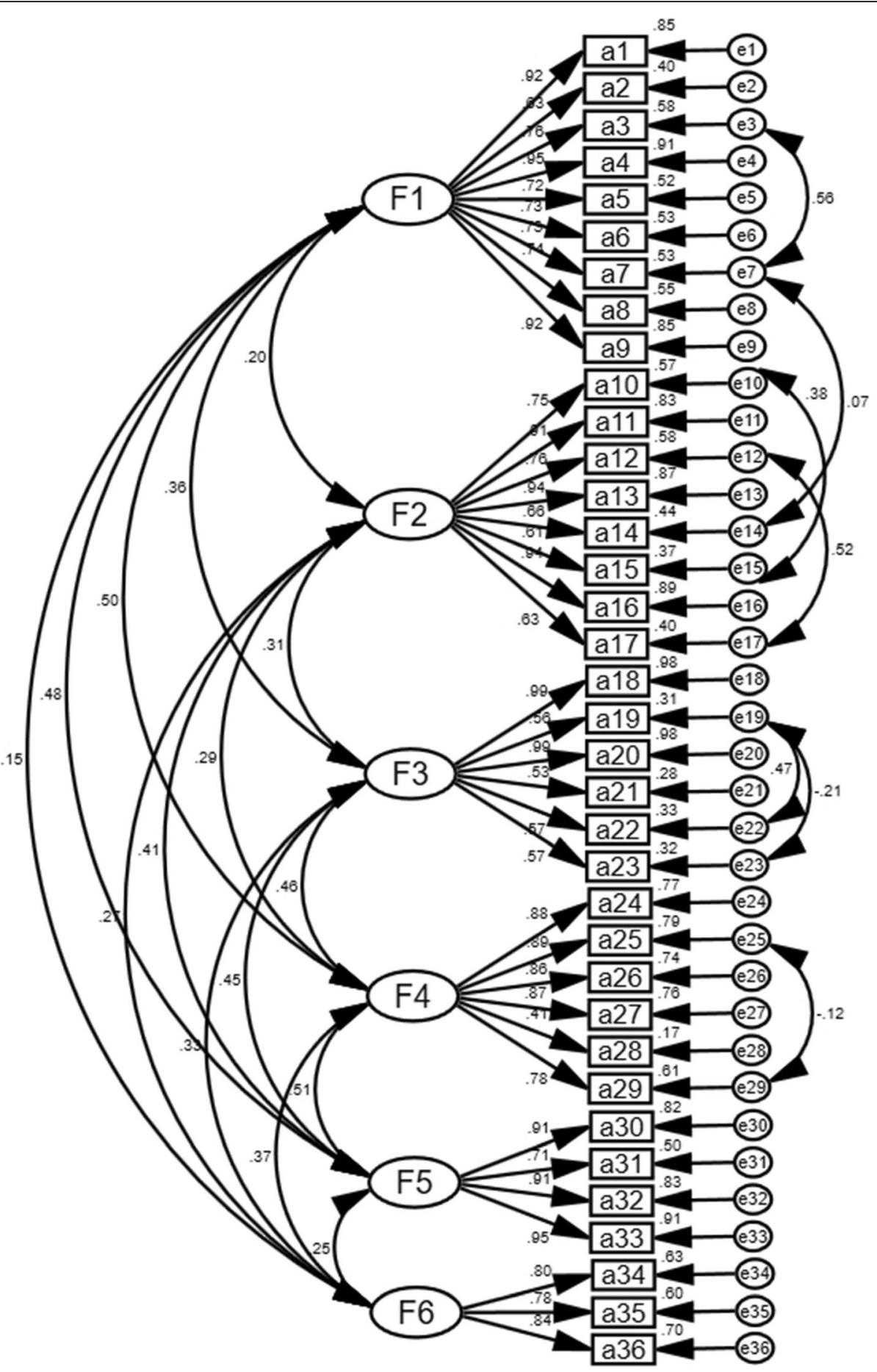

Fig. 3 Standardized six-factor structural model of the medication safety competence scale ( $n=447$ )

importance for our future studies. Additionally, selfreporting data contain several potential sources of bias that should be taken into account. Finally, principal component analysis (CFA) was used to extract the common factors in this study, and the results may be overestimated.

\section{Conclusions}

The English version of the Medication Safety Competence Scale has sound psychometric properties and has been successfully introduced into China. The scale will contribute to clinical practice by providing evidence to guide education of nurses in medication safety. 
Table 5 Reliability analysis for Chinese version of the Medication Safety Competence Scale

\begin{tabular}{|c|c|c|c|c|}
\hline The scale and Its dimension & Score (SD) & Cronbach's Alpha & $\begin{array}{l}\text { split-half } \\
\text { reliability }\end{array}$ & $\begin{array}{l}\text { test-retest } \\
\text { reliability }\end{array}$ \\
\hline The Medication Safety Competence Scale & $103.73(17.71)$ & 0.940 & 0.671 & 0.703 \\
\hline Patient-centered medication management & $24.42(6.56)$ & 0.948 & & \\
\hline Improvement of safety problems & $24.41(5.06)$ & 0.933 & & \\
\hline Management of effecting factors & $18.53(4.36)$ & 0.881 & & \\
\hline Safety risk management & $17.85(4.19)$ & 0.889 & & \\
\hline Multidisciplinary collaboration & $8.32(3.66)$ & 0.927 & & \\
\hline Responsibility in the nursing profession & $10.20(2.12)$ & 0.843 & & \\
\hline
\end{tabular}

\section{Implications}

Most medication errors are committed by nurses. To solve this problem, it is of great significance for nursing managers to conduct the comprehensive and effective assessment for clinical nurses' medication safety competence. The developed scale will evaluate the medication safety competence of Chinese clinical nurses, providing an opportunity for development of targeted educational plans.

\section{Acknowledgements}

The authors are grateful to clinical nurses who participated in this study, and also to the nursing directors for their strong support in collecting samples. Furthermore, we thank the reviewers from the bottom of our hearts for their useful feedback and valuable editorial suggestions on our manuscript. We also thank TopEdit (www.topeditsci.com) for its linguistic assistance during the preparation of this manuscript.

\section{Authors' contributions}

ZY completed the study design with $\mathrm{HZ}$. ZY, FC and YL contributed to data collection and participated in manuscript writing. ZY conducted data analysis and interpretated results. The manuscript was drafted by $Z Y$ and edited and approved by HZ. All authors have read and approved the manuscript.

\section{Funding}

No funding was obtained for this study.

\section{Availability of data and materials}

The data garnered during the current study and the final dataset used for statistical analysis are available from the corresponding author on reasonable request. The Chinese version of the Medication Safety Competence Scale are available from the corresponding author on reasonable request.

\section{Declarations}

\section{Ethics approval and consent to participate}

Prior to the investigation, participants were informed of the purpose and significance of this study and signed informed consent. All data were protected throughout the study. All procedures were performed with the 1964 Helsinki declaration, and the study protocol was approved by the Ethics Committee of the Jinzhou Medical University (LLSC2021213).

\section{Consent for publication}

Not applicable.

\section{Competing interests}

The authors declare that they have no competing interests.

\section{Author details}

'Department of Nursing, Jinzhou Medical University, No.40, Section 3, Songlu Road, Linghe District, Jinzhou 121001, China. ${ }^{2}$ The First Affiliated Hospital, Jinzhou Medical University, Jinzhou, China.
Received: 19 May 2021 Accepted: 23 August 2021

Published online: 09 September 2021

\section{References}

1. WHO. WHO launches global effort to halve medication-related errors in 5 years. March 29, 2017. http://www.who.int/mediacentre/news/releases/201 7/medication-related-errors/en/ (accessed 10 Apr 2017).

2. Tinkler L, Smith V, Yiannakou Y, Robinson L. Professional identity and the Clinical Research Nurse: A qualitative study exploring issues having an impact on participant recruitment in research. J Adv Nurs. 2018;74(2):31828. https://doi.org/10.1111/jan.13409.

3. Bennie M, Kurdi A, MacBride-Stewart S, Avery T. Medication safety in primary care-from measurement to action. Drug Ther Bull. 2021;59(2):24-8. https://doi.org/10.1136/dtb.2020.000010.

4. Cousins DH, Gerrett D, Warner B. A review of medication incidents reported to the National Reporting and Learning System in England and Wales over 6 years (2005-2010). Br J Clin Pharmacol. 2012;74(4):597-604. https://doi. org/10.1111/j.1365-2125.2011.04166.x.

5. Mendes JR, Lopes MCBT, Vancini-Campanharo CR, Okuno MFP, Batista REA. Types and frequency of errors in the preparation and administration of drugs. Einstein (Sao Paulo). 2018;16(3):eAO4146. doi:https://doi.org/10.1590/ S1679-45082018AO4146

6. Bakhshi F, Mitchell R, Nasrabadi AN, Varaei S, Hajimaghsoudi M. Behavioural changes in medication safety: Consequent to an action research intervention. J Nurs Manag. 2021;29(2):152-164. doi:https://doi.org/10.1111/ jonm. 13128

7. Brandt NJ, Lee M. Medication Safety in Older Adults: Learning From 2020 as We Launch into 2021. J Gerontol Nurs. 2021;47(1):7-11. doi:https://doi.org/1 0.3928/00989134-20201208-02

8. Bengtsson M, Ekedahl Al, Sjöström K. Errors linked to medication management in nursing homes: an interview study. BMC Nurs. 2021;20(1): 69. doi:https://doi.org/10.1186/s12912-021-00587-2

9. Vaismoradi M, Griffiths P, Turunen H, Jordan S. Transformational leadership in nursing and medication safety education: a discussion paper. J Nurs Manag. 2016;24(7):970-980. doi:https://doi.org/10.1111/jonm.12387

10. Choo J, Hutchinson A, Bucknall T. Nurses' role in medication safety. J Nurs Manag. 2010;18(7):853-861. doi:https://doi.org/10.1111/j.1365-2834.2010.011 64. $x$

11. Smeulers M, Onderwater AT, van Zwieten MC, Vermeulen H. Nurses' experiences and perspectives on medication safety practices: an explorative qualitative study. J Nurs Manag. 2014;22(3):276-285. doi:https://doi.org/1 $0.1111 /$ jonm. 12225

12. Ganaden RE, Mitchell L. Implementing a Comprehensive Unit-Based Safety Program (CUSP) to Enhance a Culture of Patient Safety and Improve Medication Safety in a Regional Home Care Program. Qual Manag Health Care. 2018;27(3): 130-135. doi:https://doi.org/10.1097/QMH.00000000000001 80

13. Ridelberg M, Roback K, Nilsen P. Facilitators and barriers influencing patient safety in Swedish hospitals: a qualitative study of nurses' perceptions. BMC Nurs. 2014;13:23. doi:https://doi.org/10.1186/1472-6955-13-23

14. Jose J, van Eekeren R, Jimmy B. Medication safety education through games: a potential approach to educate healthcare students on adverse drug reactions. Int J Pharm Pract. 2021;29(1):91-92. doi:https://doi.org/1 0.1111/ijpp.12657 
15. Musharyanti L, Haryanti F, Claramita M. Improving Nursing Students Medication Safety Knowledge and Skills on Using the 4 C/ID Learning Model. J Multidiscip Healthc. 2021;14:287-295. doi:https://doi.org/10.2147/ JMDH.S293917

16. Davis M, Coviello J. Development of a Medication Safety Science Curriculum for Nursing Students. Nurse Educ. 2020;45(5):273-276. doi:https://doi.org/1 0.1097/NNE.00000000000000783

17. Khatony A, Soroush A, Andayeshgar B, Abdi A. Nursing students' perceived consequences of self-medication: a qualitative study. BMC Nurs. 2020;19:71. doi:https://doi.org/10.1186/s12912-020-00460-8

18. DeVellis, RF. Scale development: Theory and applications (4th ed.). SAGE Publications: 2016.

19. Park J, Seomun G. Development and Validation of the Medication Safety Competence Scale for Nurses [published online ahead of print, 2020 Nov 6]. West J Nurs Res. 2020;193945920969929. doi:https://doi.org/10.1177/019394 5920969929

20. Wolf EJ, Harrington KM, Clark SL, Miller MW. Sample Size Requirements for Structural Equation Models: An Evaluation of Power, Bias, and Solution Propriety. Educ Psychol Meas. 2013;76(6):913-934. doi:https://doi.org/10.11 77/0013164413495237

21. Kline, RB. Principles and practice of structural equation modeling (2nd ed.). New York: Guilford: 2005

22. Huang F, Wang H, Wang Z, et al. Psychometric properties of the perceived stress scale in a community sample of Chinese. BMC Psychiatry. 2020;20(1): 130. doi:https://doi.org/10.1186/s12888-020-02520-4

23. Zhou CL, Wang SQ, Wang YF, Ou JX, Wu YN. A Chinese version of the Patient Perceptions of Patient-Empowering Nurse Behaviours Scale: Reliability and validity assessment in chronically ill patients. J Clin Nurs. 2019;28(3-4):444-457. doi:https://doi.org/10.1111/jocn.14613

24. Waltz, C.F.; Strickland, O.L.; Lenz, E.R. Measurement in Nursing and Health Research (4th ed.). 2016;New York, US: Springer Publishing Company: 87-89

25. Devellis RF. Scale development: theory and applications (applied social research methods). 4th ed. Los Angeles, CA: SAGE publication; 2016. p. 137.

26. Koo TK, Li MY. A Guideline of Selecting and Reporting Intraclass Correlation Coefficients for Reliability Research. J Chiropr Med. 2016;15(2):155-163. doi: https://doi.org/10.1016/j.jcm.2016.02.012

\section{Publisher's Note}

Springer Nature remains neutral with regard to jurisdictional claims in published maps and institutional affiliations.

Ready to submit your research? Choose BMC and benefit from:

- fast, convenient online submission

- thorough peer review by experienced researchers in your field

- rapid publication on acceptance

- support for research data, including large and complex data types

- gold Open Access which fosters wider collaboration and increased citations

- maximum visibility for your research: over $100 \mathrm{M}$ website views per year

At $\mathrm{BMC}$, research is always in progress.

Learn more biomedcentral.com/submissions 